In a repont which must surely rate as one of the federal government's most candid assessments of the troubles afflicting nuclear power in the United States, a task force of the Energy Research and Development Administration (ERDA) concluded last week that the nuclear industry faces a stunted future unless public concern over reactor safety, safeguards against the theft of nuclear material and waste disposal are soon cleared up. Moreover, the report also notes that shortages of uranium could restrict the growth of nuclear power after the mid-1990s, that spent fued is piling up at reactor sites to such an extent that some reactors may soon have to be shut down, and that the government may have to share the financial burden of building new unanium enrichment plants because the nuclear industry is unlikely to raise sufficient capital on its own.

Although those problems are not new, the task force represents a welcome break from many previous government pronouncements on nuclear power, which have mostly followed the line that the problems have been exaggerated by a group of eccentrics who do not know what they are talking about. This report, however, accepts that the "fears of the lay public and its decision-makers are supported by a fair segment of the scientific communitymany of whom otherwise support the use of nuclear reactors for the generation of electric power".

On the question of unanium resources, the repont notes that unless either plutonium is extracted from spent fuel and recycled as a fuel for light water reactors, or the breeder reactor is brought on line as soon as possible, there is only enough uranium in the United States to guarantee a lifetime's fuel for a limited number of reactors. The task force therefore urges the Nuclear Regulatory Commission (NRC)-which has responsibility for regulating the nuclear industry-to make up its collective mind as soon as possible on whether or not plutonium recycling should be allowed. But, between the writing and publication of the report, the NRC announced that it probably will not make a decision before 1978 on plutonium recycling. The nuclear industry is therefore faced with great uncertainties about how long the fuel for light water reactors will last.

But the NRC's delay in ruling on plutonium recycling has other consequences. Until the decision is finally made, the NRC will not issue a licence for operation of any fuel reprocessing plants, which means that spent reactor fuel will continue to be stored at reactor sites for several more years.
But the task force report notes that 10 reactors do not have any more room for spent fuel storage, and many others will soon face the same problem. The "industry should be advised that additional spent fuel storage capacity is required and that ERDA regards this as an industry responsibility and has no plans for providing such storage", the task force suggests.

On the question of waste disposal, the task fiorce notes that the problems "are tied almost completely to whether or not spent fuel is processed", so that, too, hangs on the plutonium recycling decision. In any case, no method for permanent disposal of radioactive wastes has yet been demonstrated, and the report suggests that problems in

\section{Washington seen} by Colin Norman

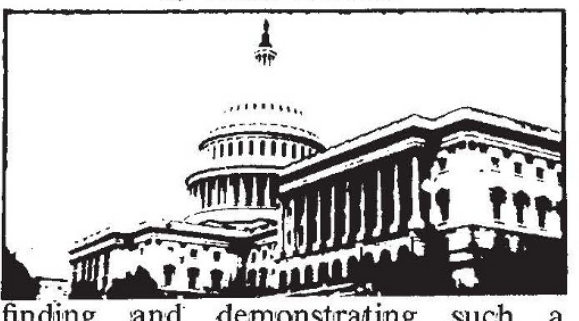
method "together with the lack of decision on the part of the government [have] in fact come close to making waste management the pacing item of the nuclear fuel cycle".

Nevertheless, the task force believes that the problems can be overcome, but that "public understanding and acceptance are essential to the future effective and timely use of fission energy as a source of electric power". The task force therefore calls for "candour and objectivity on the part of the government in dealing with the public". Its own report is a good start.

Following a number of recent reports in the medical literature that aspirin may help prevent blood clots from forming, the National Heart and Lung Institute has launched a massive clinical study to see whether the drug offers any protection against heart attacks.

During the next year, about 4,200 people aged between 30 and 69 who have previously suffered an acute heart attack will be enrolled in the study, which will be carried out by 30 hospitals and research centres around the United States. Half the volunteers will each receive $1 \mathrm{~g}$ of aspirin a day (equivalent to three regular tablets) for three years, while the rest will be given placebos. The chief objective will be to see ments, which were formally confirmed whether there is any difference in total by the Senate, have been warmly mortality between the two groups, and endorsed by biomedical scientists. investigators will also be looking for such factors as differences in the incidence of non-fatal heart attacks and strokes between the two groups. According to Dr William Friedewald, the study director, about $85 \%$ of those who now survive one heart attack eventually die from a second heart attack from other cardiovascular problems.

Volunteers will be given quarterly medical checks while they are taking the drug and more extensive annual checks during a three-year follow-up period. A committee at the Heart and Lung Institute will periodically monitor the study and, unless adverse drug effects show up, the clinical phase is expected to be completed in September 1979.

Aspirin may help guard against heart attacks because it hinders the clumping together of blood platelets, which is believed to be a crucial early event in the formation of arterial blood clots.

- The failure last week of the final stage of a Titan III-C rocket during the launch of a pair of military communications satellites is not expected to affect future space science missions, according to NASA officials. At a meeting held on May 21, the day after the mishap occurred, it was decided that the Viking Mars Lander mission should go ahead in July as planned, even though it will be launched by a rocket whose first three stages are similar to those of the Titan III-C.

Officials of NASA are still not certain what caused the failure, however. Control over the final stage was lost before its engines fired, it began to roll helplessly and eventually burned up on re-entry into the Eanth's atmosphere.

The mission, which cost $\$ 57$ million, was to have completed a global military communications network consisting of four satellites. The first two were launched in 1973 into stationary orbits over the Atlantic and Pacific, and last week's launch should have placed the other two over the Indian Ocean and the Pacific.

- Virtually unnoted by the general press, or by Congress, two key government positions affecting biomedical reselarch were filled earlier this month. Dr Donald Fredrickson, President of the Institute of Medicine (part of the National Academy of Sciences) was appointed Director of the National Institutes of Health, and Dr Theodore Cooper, a former Director of the National Heart and Lung Institute, was appointed Assistant Secretary for Health-the top health job in the federal government. Both appoint- 